\title{
GREEN BUILDING DESIGN AND ASSESSMENT WITH COMPUTATIONAL BIM: THE WORKFLOW AND CASE STUDY
}

\author{
YAIK-WAH LIM ${ }^{1,2}$, TAKI EDDINE SEGHIER ${ }^{3}$, MOHD HAMDAN AHMAD ${ }^{1}$, \\ PAU CHUNG LENG ${ }^{1}$, AZARI MAT YASIR ${ }^{1}$, NORASLINDA ABDUL RAHMAN ${ }^{1,2}$, \\ WAI LAI CHAN ${ }^{1} \&$ SHARIFAH SALWA SYED MAHDZAR ${ }^{1,2}$ \\ ${ }^{1}$ Faculty of Built Environment and Surveying, Universiti Teknologi Malaysia (UTM), Malaysia \\ ${ }^{2}$ Centre for the Study of Built Environment in the Malay World (KALAM), \\ Institute for Smart Infrastructure and Innovative Construction (ISIIC), UTM, Malaysia \\ ${ }^{3}$ School of Architecture and Built Environment, UCSI University, Malaysia
}

\begin{abstract}
Due to growing concern regarding sustainability in the built environment, several green building assessments and rating tools have been established worldwide including Green Building Index (GBI) in Malaysia which was introduced in 2009. However, the current methods of measuring, analysing and documenting the green building design rely on a number of disjointed processes to meet the discrete requirements for various building systems. The development of building information modelling (BIM) together with computational programming has made it easier for complicated building modelling to be digitally constructed, generating required information to support green building design and assessment throughout various project stages. Thereby, the aim of this research is to integrate computational BIM with green building design and assessment in Malaysia, using GBI as a unique case and an office building in Kuala Lumpur, Malaysia as a case study. Match-up of BIM (Revit) functionalities and GBI (NRNC) criteria was formulated, then visual programming (Dynamo) was employed to automate the BIM data management process. The findings of this research have developed workflows and templates to assess several criteria, namely energy efficiency (EE), indoor environmental quality (EQ), sustainable site planning and management (SM) and material and resources (MR), which allow a higher level of automation in green building assessment.

Keywords: building information modelling, visual programming, office building, sustainability, Green Building Index.
\end{abstract}

\section{INTRODUCTION}

Green building development is an urgent move for sustainable built environment, and many green building assessments such as Leadership in Energy and Environmental Design (LEED) in the US, Building Research Establishment Environmental Assessment Method (BREEAM) in the UK, Comprehensive Assessment System for Built Environment Efficiency (CASBEE) in Japan, Green Mark in Singapore, and Green Building Index (GBI) in Malaysia have been established to assess the green building performances. Sustainability in the building sector has received concerns from various stakeholders because the building industry accounts for $36 \%$ of energy use and $39 \%$ of energy-related carbon dioxide $\left(\mathrm{CO}_{2}\right)$ emissions worldwide [1]. Furthermore, the world building energy consumption is expected to increase by nearly $50 \%$ between 2018 and 2050 if no further action is taken to improve building energy efficiency [2].

To assess the success of a green building project in achieving sustainability, assessment tools which the designers can use to predict and evaluate the building performances are needed [3]. With a predictive assessment of the building performance, the decision makers can put forward strategies and methods in their decisions to improve the building performance in a more cost-effective way [4]. Even though various green building assessments or ratings such as LEED and BREEAM have been established since the 1990s, 
the current methods of measuring, analysing and documenting the green building rely on a number of disjointed processes which cause regression in productivity [5].

With the development of building information modelling (BIM) process and technology, all information or data related to a building, including its physical features and performances during its life cycle, can be digitally represented in a single model [6]-[8]. Furthermore, the building information can be extracted and managed using computational algorithms such as visual programming language (VPL) to automate the performance evaluation process. Thus, integration of computational BIM and green building design can best address the unprecedented challenges in productivity and sustainability encountered by the building industry [9]-[12].

Till today there is no standard workflow for computational BIM-based modelling for green building design and assessment, more efforts are needed to further develop a model or framework for the integration of these two aspects. Therefore, this study aims to integrate GBI Malaysia assessment process and BIM functionalities with the implementation of VPL. It explores the implementation of computational BIM to achieve a higher level of automation in the green building assessment process using GBI Malaysia as a unique case and a recently constructed office tower in TRX Kuala Lumpur as a case study.

\subsection{Green Building Index (GBI)}

In Malaysia, GBI is one of the assessment tools being adopted by the building industry since it was jointly founded and developed by Pertubuhan Akitek Malaysia (PAM) and the Association of Consulting Engineers Malaysia (ACEM) in 2009. GBI includes rating tools for non-residential new construction (NRNC), residential new construction (RNC), existing non-residential buildings (NREB), NRNC hotel, NRNC resort, NRNC retail, township, industrial new construction (INC) and so on. Some of the criteria in GBI used the benchmarks as stated in Malaysian Standard (MS) 1525:2019 such as overall thermal transfer value (OTTV) and roof thermal transfer value (RTTV) [13].

The GBI classification is as shown in Table 1. This research focuses on a new office building, thus adopting the GBI (NRNC) tool. It has six major parts consisting of energy efficiency (EE), indoor environmental quality (EQ), sustainable site planning and management (SM), materials and resources (MR), water efficiency (WE) and innovation (IN) as outlined in Table 2.

In this research, a generic integration framework was established on the match-up of the GBI credit requirements and the functionalities available from current BIM solutions, for the purposes of this research, the Autodesk Revit software suite and supplemental software application from Autodesk. Two major tasks in establishing the framework include evaluating GBI credits requirements, and screening available functionalities of Revit and supplemental BIM solutions. The gaps in the framework where no existing functionality was available to help compliance with certain GBI credits were identified.

Table 1: GBI classification.

\begin{tabular}{|c|c|}
\hline Points & GBI Rating \\
\hline $86+$ & Platinum \\
\hline 76 to 85 & Gold \\
\hline 66 to 75 & Silver \\
\hline 50 to 65 & Certified \\
\hline
\end{tabular}


Table 2: GBI (NRNC) assessment criteria overall points.

\begin{tabular}{|c|l|c|}
\hline Part & Item & Max. points \\
\hline 1 & Energy efficiency (EE) & 35 \\
\hline 2 & Indoor environmental quality (EQ) & 21 \\
\hline 3 & Sustainable site planning and management (SM) & 16 \\
\hline 4 & Material and resources (MR) & 11 \\
\hline 5 & Water efficiency (WE) & 10 \\
\hline 6 & Innovation (IN) & 7 \\
\hline Total & 100 \\
\hline
\end{tabular}

\section{METHOD}

An office tower in TRX Kuala Lumpur completed in 2019 was selected as a case study building for BIM authoring using Autodesk Revit with Level of Development (LOD) 300. It is a 27-storey height office tower which consists of lobby and facilities at Ground floor to the 2nd floor, multi-storey car park at the 3rd to 8th floor, and office spaces at the 9th to 26th floor. It was selected due to its efficient rectangular floor layout with central core design, and the unique full glazed façade design. Though this building was not originally designed with a green building concept, the purpose of the case study building is to develop and validate the BIM-GBI workflow and model rather than to achieve GBI rating. Fig. 1 illustrates the case study building modelling in Revit.
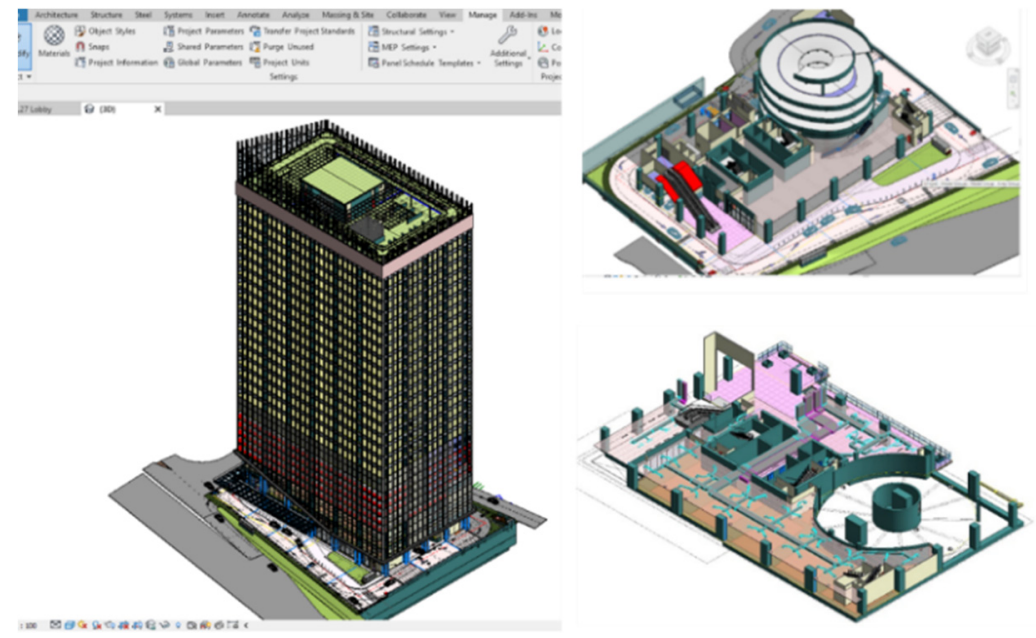

Figure 1: Revit modelling of the case study building at TRX Kuala Lumpur.

\subsection{Conceptual framework development}

A conceptual framework to categorise the GBI assessment criteria and to match-up with the BIM process was established to study the general workflow of the BIM-based GBI assessment process (Fig. 2). The information required for the GBI assessment were categorised according to the discipline of architectural, structural, electrical, mechanical and plumbing. Besides, the required element BIM LOD and attributes (geometrical and non-geometrical) were determined. 


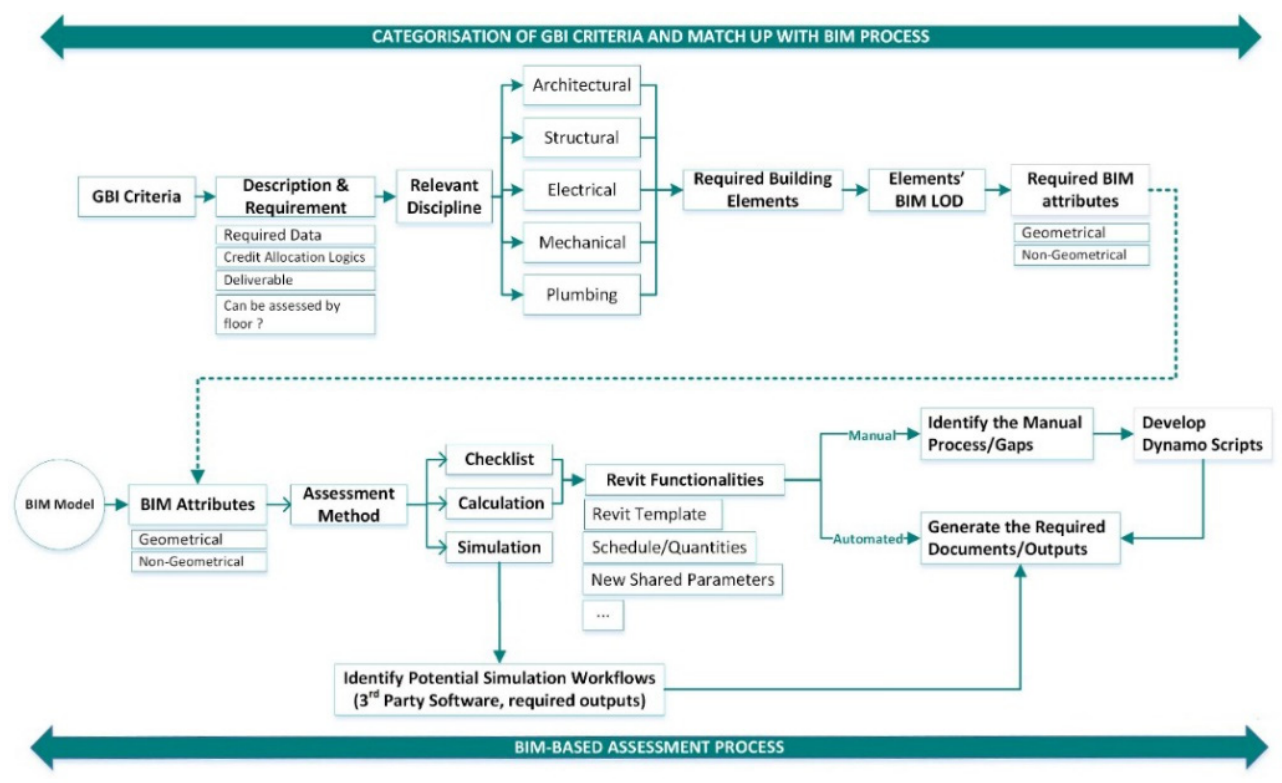

Figure 2: Conceptual framework of the BIM-based GBI assessment process.

The BIM-based GBI assessment method was divided into "checklist", "calculation" and "simulation". Various Revit functionalities such as template, schedules/quantities and shared parameters can be employed to support the "checklist" and "calculation", whereas "simulation" requires plug-ins such as Autodesk Insight or other 3rd party simulation software. Apart from that, Autodesk Dynamo, a visual programming tool which is integrated with Revit, was used to develop computational scripts to increase the level of automation for the BIM-based assessment process. This conceptual framework has been used as the basis to further develop the BIM-GBI model.

\section{BIM-GBI ASSESSMENT MODEL}

To determine which GBI (NRNC) criteria is potential to be used for developing the BIMGBI use case and model, a detailed mapping between the assessment criteria and BIM functionalities was conducted. There are some GBI criteria which can be evaluated directly using Revit functionalities such as 2D drawing, schedule/quantities, material take-off, spacing and zoning, 2D tagging and the plug-in Insight Analysis. However, some criteria require external (3rd party) tools such as simulation software. Furthermore, some evaluations can be done partially in Revit, thus they are categorised as "indirectly evaluated by Revit".

The findings show that 25 points in the EE can be directly evaluated using Revit while 3 points (EE9) can be evaluated indirectly (Table 3). The EE9 requires evidence of building maintenance room and facilities in the design floor plan ( 1 point, which can be shown in Revit drawing); it also requires evidence of commitment to engage at least $50 \%$ of permanent building maintenance team and documented plan for at least 3-year facility maintenance ( 2 points); these cannot be provided using Revit. Thus, EE9 is considered as indirectly evaluated by Revit. EE consists of the highest number of points that can be evaluated by Revit. 
Table 3: Summary of GBI (NRNC) points evaluation using Revit.

\begin{tabular}{ccccc}
\hline \multirow{2}{*}{ Part } & \multirow{2}{*}{ Item } & \multirow{2}{*}{ Max Points } & \multicolumn{2}{c}{ Points can be evaluated by Revit } \\
\cline { 4 - 5 } & & & Directly & Indirectly \\
\hline 1 & EE & 35 & 25 & 3 \\
\hline 2 & EQ & 21 & 5 & 10 \\
\hline 3 & SM & 16 & 11 & 1 \\
\hline 4 & MR & 11 & 7 & 0 \\
\hline 5 & WE & 10 & 0 & 4 \\
\hline 6 & IN & 7 & 0 & 0 \\
\hline & & 100 & 48 & 18 \\
\hline
\end{tabular}

Out of the total of 21 points for EQ, 5 points can be evaluated directly while another 10 points can be evaluated indirectly. Many points are considered as indirectly evaluated by Revit because they require external tools; for instance, EQ8: Daylighting, EQ9: Daylight glare control, and EQ10: Electric lighting levels need simulation software such as IES VE and DesignBuilder.

For the SM part, a total of 11 points can be evaluated directly while 1 point can be evaluated indirectly. Many of the SM criteria can be directly shown in the Revit modelling or drawing (site plan) such as SM1: Site selection, SM3: Development density and community connectivity, SM8: Public transportation access, SM12: Greenery and roof, etc. Besides, there are some criteria that can be quantified using Revit schedules/quantities such as SM9: Green vehicle priority and SM10: Parking capacity.

The criteria of MR can be potentially assessed directly using the Material Take-off function in Revit because this function allows building materials in the BIM model to be quantified and sorted out one by one. GBI (NRNC) MR consists of a maximum 11 points; 7 points can be evaluated directly using Revit. Material Take-off can directly quantify the contents of materials for MR1 to MR4. Whereas MR5: Storage and collection of recyclables can be shown on the drawings.

The use of Revit to evaluate water efficiency (WE) is quite limited due to these criteria requires technical reports with calculations and diagrams to support the assessment. Hence, only 4 points out of the total 10 points can be evaluated indirectly using Revit. Drawings such as the roof plan can be produced by Revit to support the technical reports for WE1: Rainwater harvesting and WE2: Water recycling.

In the last part of GBI criteria, which is the innovation (IN), the requirements are depending on the types of innovative design to reduce energy or improve sustainability. IN1: Innovation in design and environmental design initiatives requires a report on each innovation such as condensate water recovery, light pipes, self-cleaning façade, etc. Though some of these innovations might be supported by Revit drawings or schedules, in general this criterion cannot be assessed using Revit. IN2: GBI facilitator also cannot be evaluated by Revit.

\section{CASE STUDY RESULT AND ANALYSIS}

The research has developed nine use cases for the GBI (NRNC) criteria which can be directly evaluated using BIM, namely EE1: Overall thermal transfer value (OTTV), EE5: Building energy intensity (BEI), EQ8: Daylighting, SM9: Green vehicle priority, SM10: Car park capacity, MR1: Materials reuse, MR2: Recycled material, MR3: Regional material, and MR4: Sustainable timber. However, only two of them, which use different methods and workflows, are presented in this paper as case study. 


\subsection{EE1: Overall thermal transfer value (OTTV)}

To evaluate the OTTV, the case study building envelope was divided into 3 main parts (as shown in Fig. 3):

1. Ground to 2nd floor with partial air-conditioned (lobby and facilities) and partial natural ventilated (car park);

2. 3rd to 8th floor with natural ventilated car park (not to be included for OTTV calculation);

3. 9th to 26th floor with air-conditioned office spaces (typical floor).

As the OTTV should only include air-conditioned spaces, 3rd to 8th floors were excluded from the evaluation. With that, the building envelope was divided into Part 1 (ground to 2nd floor) and Part 2 (a typical office floor which was multiplied by 18 floors).

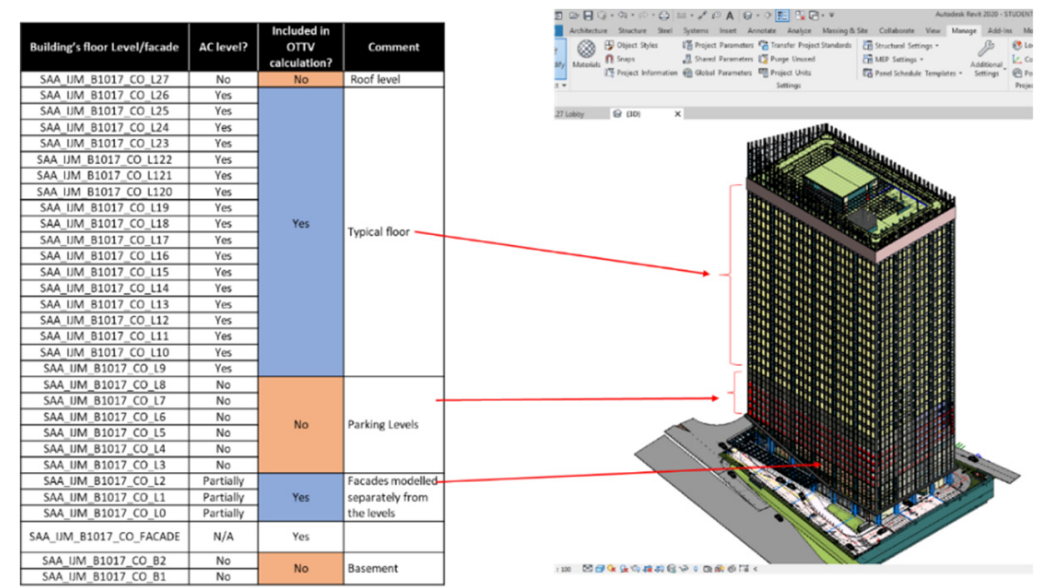

Figure 3: Division of the case study building envelope for OTTV assessment.

The BIM-GBI OTTV assessment workflow is outlined in Fig. 4. New shared parameters and schedules had been created in the Revit template for model preparation and data verification. However, some assumptions were made for the building properties data inputs due to limited information available. Then Dynamo scripts (Fig. 5) were developed to extract the BIM data automatically for OTTV calculation in "BIM-GBI Template" Excel spreadsheet. Fig. 6 shows the combination of both Part 1 and Part 2 OTTV. Due to Part 2 was only representing a single typical floor, it was multiplied by a repetition factor of 18 .

\subsection{SM9-10: Green vehicle and parking capacity}

Under GBI (NRNC) SM9: Green vehicle priority, a building which provides preferred parking for low-emitting and fuel-efficient for $5 \%$ of full-time equivalent (FTE) occupants is entitled for 1 point. "Preferred parking" refers to the parking spots that are closest to the main entrance of the project. Apart from that, 1 point will be awarded for a building that sizes parking capacity not exceeding the minimum local zoning requirement and provides preferred parking for carpools or vanpools for $5 \%$ of the total provided parking spaces under SM10: Parking capacity. 


\section{OTTV Assessment Workflow :}

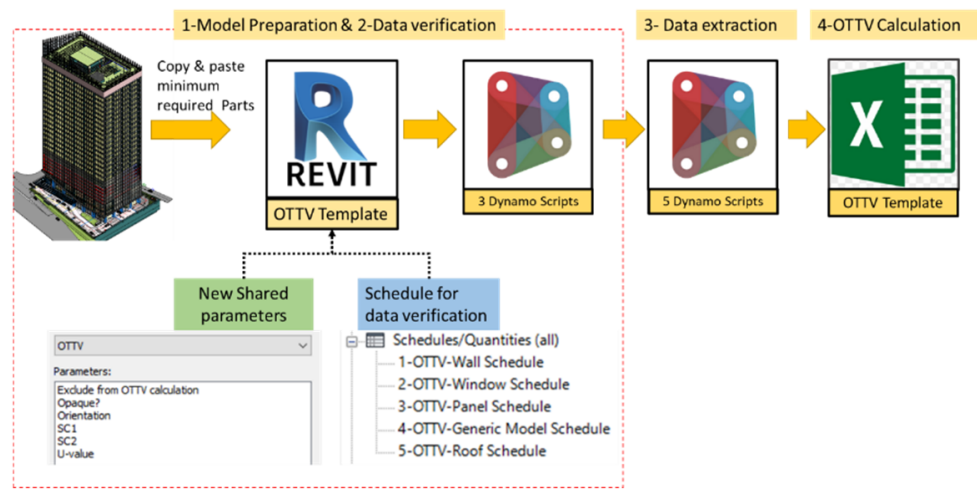

Figure 4: BIM-GBI OTTV assessment workflow.

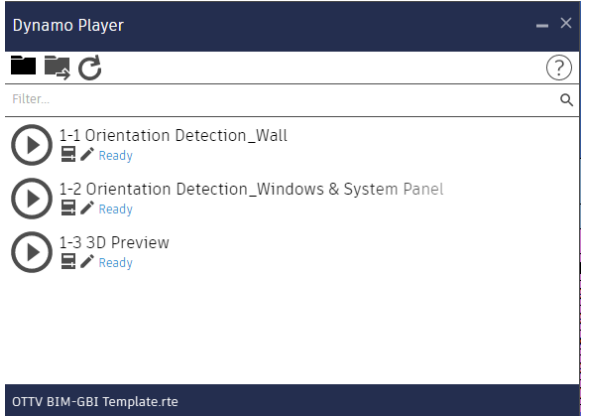

(a)

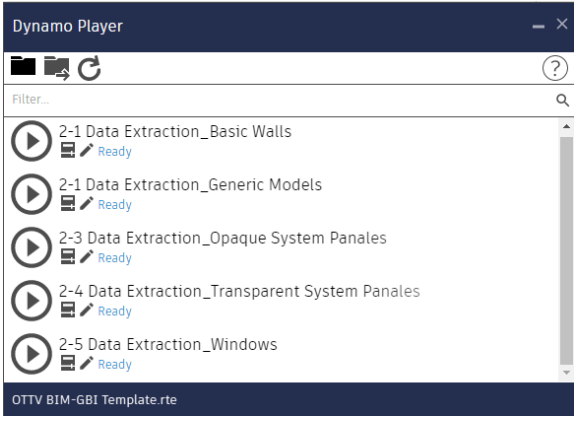

(b)

Figure 5: Dynamo scripts for OTTV assessment model preparation and data extraction. (a) Model preparation; and (b) Data extraction.

\begin{tabular}{|c|c|c|c|}
\hline \multicolumn{2}{|c|}{ OVERALL BUILDING'S OTTV (W/m²) } & 55.22 & \\
\hline Building Parts & r: Repetition factor & An: Total Envelop Part Area $\left(\mathrm{m}^{2}\right)$ & Overall OTTV $\left(\mathrm{W} / \mathrm{m}^{2}\right)$ \\
\hline Part 1 & 1 & 2187.08 & 62.69 \\
\hline Part 2 & 18 & 791.48 & 54.08 \\
\hline Part $n$ & 0 & 0.00 & 0.00 \\
\hline
\end{tabular}

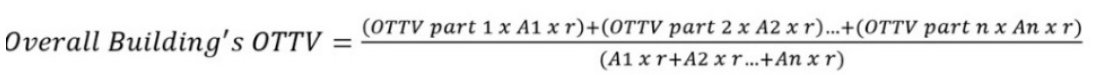

Figure 6: OTTV assessment result based on input data assumption.

Fig. 7 presents the workflow of assessing SM9 and SM10 using the BIM-GBI model. It starts from data input for the green vehicle (low-emitting and fuel-efficient) parking, preferred parking, and carpools/vanpools parking in the Revit schedules. The newly created Revit schedules include SM09-All parking (Fig. 8), SM09-Only FTE occupants parking, 
SM09-Parking green vehicle, SM10-Only car park and SM10-Parking carpools/vanpools. Then, Dynamo scripts (Fig. 9(a)) were formulated to extract and process the data to quantify the points achieved. The parking capacity was calculated based on the floor area and local authority requirement. Finally, the assessment results are displayed in the Dynamo Player (Fig. 9(b)).

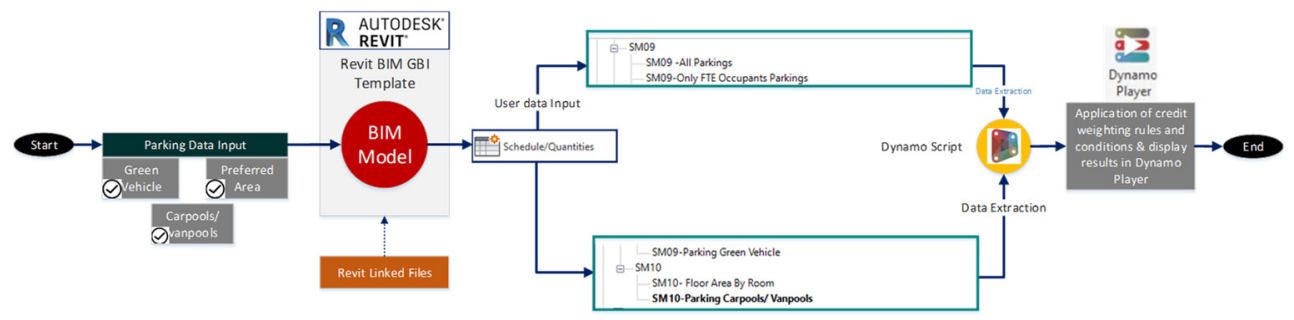

Figure 7: BIM-GBI green vehicle and parking capacity assessment workflow.

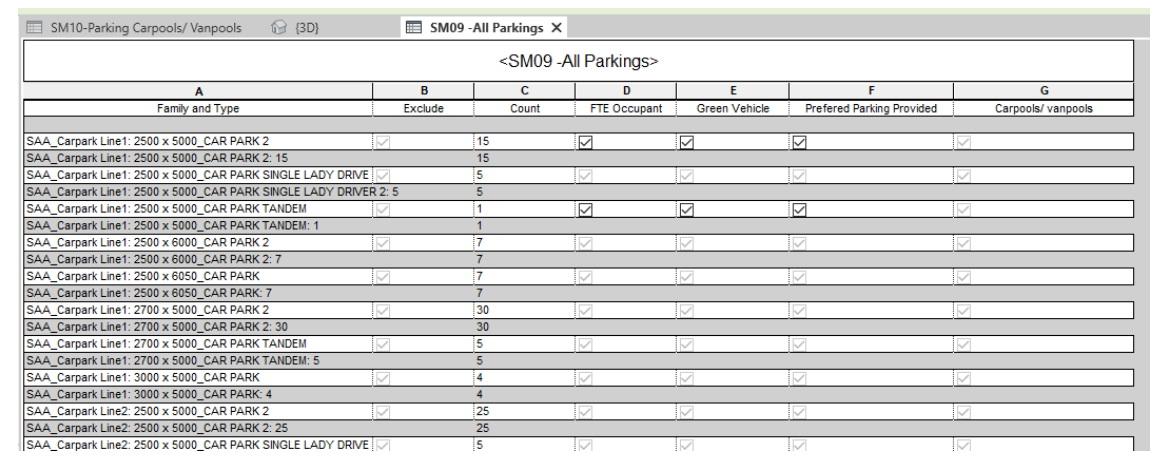

Figure 8: Revit schedule SM9-all parking.

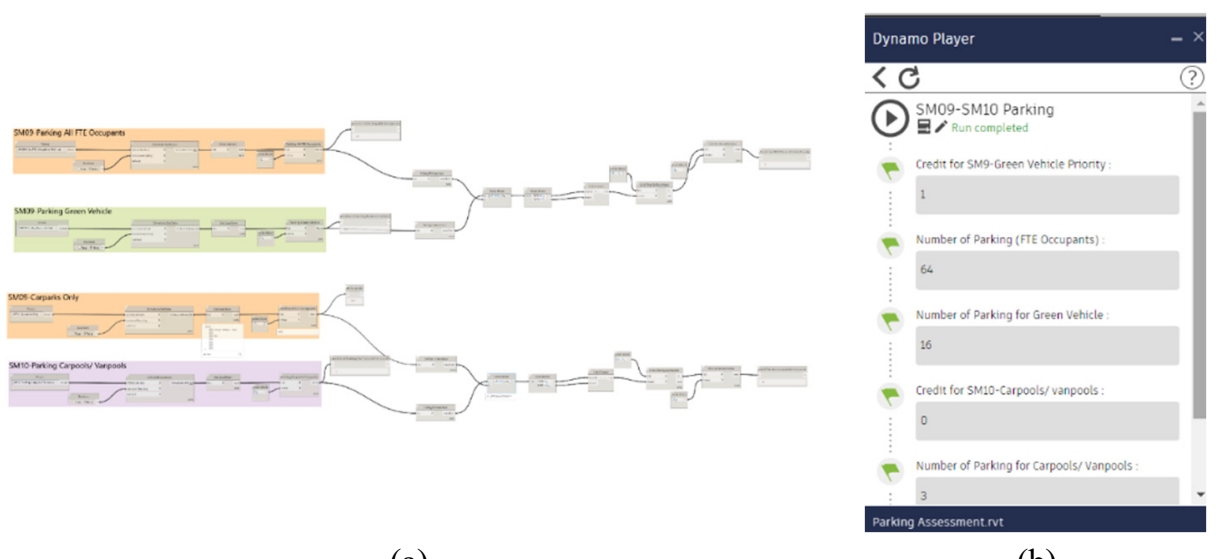

(a)

(b)

Figure 9: Use of VPL for SM9 and SM10: (a) Dynamo scripts; and (b) Assessment results in Dynamo Player. 


\section{DISCUSSION AND CONCLUSION}

BIM can support the design process and decision-making to achieve green building criteria in the early design phases. Although previous research [14], [15] has explored BIM-based method for green building assessment in different contexts, the current study has specifically applied BIM functionalities for GBI Malaysia assessment criteria with test cases developed using an actual building located in Kuala Lumpur as case study. Furthermore, the study also integrated visual programming language (VPL) as a solution for data management and higher level of automation.

Based on the detailed match-up between the BIM functionalities and GBI (NRNC) criteria, results showed that only 48 points can be directly evaluated while 18 points can be indirectly evaluated using various Revit functionalities. Thus, the development of the BIMGBI model focused on the GBI (NRNC) criteria that can be directly evaluated using Revit and require quantifications using calculation or simulation assessment methods. As a result, the newly developed BIM-GBI model covers 26 points of the GBI (NRNC) using the calculation (schedules, material take-off, Dynamo, spreadsheet) and simulation methods as presented in Table 4.

Table 4: Summary of GBI (NRNC) points evaluation using Revit.

\begin{tabular}{|c|l|c|l|l|}
\hline $\begin{array}{c}\text { GBI } \\
\text { criteria }\end{array}$ & Description & $\begin{array}{c}\text { GBI } \\
\text { point }\end{array}$ & $\begin{array}{l}\text { Assessment } \\
\text { method }\end{array}$ & Tool/functionalities \\
\hline EE1 & $\begin{array}{l}\text { Minimum EE } \\
\text { performance }\end{array}$ & 1 & Calculation & Schedule, Dynamo, Spreadsheet \\
\hline EE5 & $\begin{array}{l}\text { Advanced EE } \\
\text { performance - BEI }\end{array}$ & 15 & Calculation & $\begin{array}{l}\text { Schedule, Dynamo, BEIT, } \\
\text { Spreadsheet }\end{array}$ \\
\hline EQ8 & Daylighting & 2 & Simulation & $\begin{array}{l}\text { Insight Lighting Analysis, } \\
\text { Schedule }\end{array}$ \\
\hline SM9 & Green vehicle priority & 1 & Calculation & Schedule, Dynamo \\
\hline SM10 & Parking capacity & 1 & Calculation & Schedule, Dynamo \\
\hline MR1 & $\begin{array}{l}\text { Materials reuse and } \\
\text { selection }\end{array}$ & 2 & Calculation & $\begin{array}{l}\text { Material Take-off, Dynamo, } \\
\text { Spreadsheet }\end{array}$ \\
\hline MR2 & $\begin{array}{l}\text { Recycled content } \\
\text { materials }\end{array}$ & 2 & Calculation & $\begin{array}{l}\text { Material Take-off, Dynamo, } \\
\text { Spreadsheet }\end{array}$ \\
\hline MR3 & Regional materials & 1 & Calculation & $\begin{array}{l}\text { Material Take-off, Dynamo, } \\
\text { Spreadsheet }\end{array}$ \\
\hline MR4 & Sustainable timber & 1 & Calculation & $\begin{array}{l}\text { Material Take-off, Dynamo, } \\
\text { Spreadsheet }\end{array}$ \\
\hline & & 26 & & \\
\hline
\end{tabular}

It is worth mentioning that the aim of this research is to implement computational BIM to achieve a higher level of automation in GBI assessment process, hence the case study office building in TRX Kuala Lumpur was employed for the purpose of developing the workflows and test cases rather than for accurate evaluation of GBI points. Due to the constraints of time and resources, some modifications on the Revit model and assumptions of building data were made for the unavailable information required for GBI assessment such as the building components, material properties as well as mechanical and electrical 
systems. Nevertheless, the geometrical information such as the building area, layout and volume were based on the actual building condition.

This research has made significant contributions to the implementation of BIM for green building assessment with special reference to GBI Malaysia. It has provided detailed comparison of BIM functionalities with GBI (NRNC) assessment criteria which is an advancement of knowledge in the relevant study; its findings can be further applied or adopted to different building typologies and contexts. The integration of visual programming language with BIM, also known as computational BIM method, opens the possibility to increase the level of automation for BIM data extraction and management for green building assessment. Although the current research only developed use cases for 9 GBI criteria, the similar workflow can be further extended for other relevant green building assessment criteria including other green building assessment tools apart from GBI.

\section{ACKNOWLEDGEMENTS}

The authors would like to acknowledge the research funding by the Ministry of Higher Education, Malaysia (MOHE) under Fundamental Research Grant Scheme (FRGS/1/2018/SSI11/UTM/02/4), titled "Computational Building Information Modellingbased Method for Green Retrofitting", and Technology Depository Agency (TDA) Berhad and IJM Construction Sdn. Bhd. under Contract Research Grant (4C270) titled "Building Information Modelling (BIM) for Green Building Assessment”.

\section{REFERENCES}

[1] IEA, Towards a zero-emission, efficient, and resilient buildings and construction sector, 2017. Global Status Report 2017, UN Environment and International Energy Agency, 2017.

[2] USEIA, International Energy Outlook 2019 with Projections to 2050, US Energy, 2019.

[3] Lim, Y.W., Sediadi, E., Shahsavari, F. \& Fazlenawati, N., Building information modelling for building energy efficiency evaluation: Integration with green building index (GBI) in Malaysia. Proceedings of the 4th ACE, pp. 42-48, 2016.

[4] Akadiri, P.O., Chinyio, E.A. \& Olomolaiye, P.O., Design of a sustainable building: A conceptual framework for implementing sustainability in the building sector. Buildings, 2(2), pp. 126-152, 2012.

[5] Lim, Y.W. et al., BIM and genetic algorithm optimization for sustainable building envelope design. International Journal of Sustainable Development and Planning, 13(1), pp. 151-159, 2018.

[6] Cavalliere, C., Habert, G., Dell'Osso, G.R. \& Hollberg, A., Continuous BIM-based assessment of embodied environmental impacts throughout the design process. Journal of Cleaner Production, 211, pp. 941-952, 2019.

[7] Lim, Y.W., Chong, H.Y., Ling, P.C.H. \& Tan, C.S., Greening existing buildings through building information modelling: A review of the recent development. Building and Environment, 200, 107924, 2021.

[8] Santos, R., Costa, A.A., Silvestre, J.D. \& LincyPyl, T.V., BIM-based life cycle assessment and life cycle costing of an office building in Western Europe. Building and Environment, 169, 106568, 2020.

[9] Lim, Y.W., Seghier, T.E., Harun, M.F., Ahmad, M.H., Samah, A.A. \& Majid, H.A., Computational BIM for green retrofitting of existing building envelope. WIT Transactions on the Built Environment, vol. 192, WIT Press: Southampton and Boston, pp. 33-34, 2019. 
[10] Seghier, T.E., Ahmad, M.H. \& Lim, Y.W., Automation of concrete usage index (CUI) assessment using computational BIM. International Journal of Built Environment and Sustainability, 6(1), pp. 23-30, 2019.

[11] Wei, L., Liu, S., Wei, Q. \& Wang, Y., Concept, method and application of computational BIM. Advances in Intelligent Systems and Interactive Applications. Advances in Intelligent Systems and Computing, eds F. Xhafa, S. Patnaik \& M. Tavana, Springer: Cham, p. 1084, 2019.

[12] Seghier, T.E. \& Lim, Y.W., A BIM-based method for building energy intensity (BEI) evaluation. 2nd International Civil Engineering and Architecture Conference, 2021.

[13] GBI, Green Building Index: Design Reference Guide, 1st ed., Green Building Index Sdn. Bhd.: Kuala Lumpur, Malaysia: 2009.

[14] Azhar, S., Carlton, W.A., Olsen, D. \& Ahmad I., Building information modeling for sustainable design and LEED $^{\circledR}$ rating analysis. Automation in Construction, 20(2), pp. 217-224, 2011.

[15] Sanhudo, L. et al., Building information modeling for energy retrofitting: A review. Renewable and Sustainable Energy Reviews, 89, pp. 249-260, 2018. 